\title{
INTERDISCIPLINARIDADE NO ENSINO MÉDIO INTEGRADO: CONSIDERAÇÕES PARA UMA FORMAÇÃO OMNILATERAL
}

\author{
Chera Rosane Leles de Bessa*, Rivadavia Porto Cavalcante, Jair José Maldaner, Khellen \\ Cristina Pires Correia \\ *E-mail: cheralelesif@gmail.com
}

Instituto Federal de Educação, Ciência e Tecnologia de Tocantins

DOI: $10.15628 /$ rbept.2020.9496

Artigo submetido em fev/2020 e aceito em mar/2020

\begin{abstract}
RESUMO
Este texto tem como objetivo colocar em discussão a relevância de um currículo interdisciplinar para uma formação humana mais completa. Em tempos de globalização e internacionalização do conhecimento ocasionado pelos recentes avanços da ciência e da tecnologia, torna se necessário e urgente empreender ações que visem à revisão e a atualização do currículo com conteúdos em sintonia com a contemporaneidade. O trabalho buscou fundamentação teóricoconceitual nos estudiosos vinculados ao pensamento crítico que contribuem para a Educação Profissional e Tecnológica-EPT. Utilizou-se o método qualitativo de levantamento de referenciais bibliográficos da área estudada e de documentos oficiais reguladores e orientadores do currículo integrado. O resultado do estudo revela que a interdisciplinaridade ainda é um desafio, mas também uma possibilidade na construção de um currículo integrado.
\end{abstract}

Palavras-chave: Currículo. Interdisciplinaridade. Educação Profissional.

\section{INTERDISCIPLINARITY ON INTEGRATED SECONDARY SCHOOL: REFLECTIONS FOR AN OMNILATERAL FORMATION}

\begin{abstract}
This text aims to discuss the relevance of an interdisciplinary curriculum for a more complete human formation. In times of globalization and internationalization of knowledge caused by the recent advances in science and technology, it is necessary and urgent to undertake actions aimed at revising and updating the curriculum with content in line with contemporary times. The work sought theoretical-conceptual foundation in scholars linked to critical thinking that contribute to Professional and Technological Education-EPT. We used the qualitative method of collecting bibliographic references in the area studied and official documents regulating and guiding the integrated curriculum. The result of the study reveals that interdisciplinarity is still a challenge, but also a possibility in the construction of an integrated curriculum.
\end{abstract}

Keywords: Curriculum. Interdisciplinarity. Professional Education. 


\section{INTRODUÇÃO}

Este trabalho surge das inquietações e provocações relacionadas à necessidade de encontrar caminhos e possibilidades para a construção de propostas formativas mais democráticas que possam colaborar efetivamente para a implementação do currículo do ensino médio integrado à Educação Profissional e Tecnológica - EPT. Em tempos obscuros de crises políticas, sociais e econômicas que o Brasil tem enfrentado atualmente, se torna premente a busca por mudanças significativas na educação e no ensino. Principalmente no concerne à organização curricular numa perspectiva ampliada - politécnica e interdisciplinar - que integre no ensino os conhecimentos necessários ao desenvolvimento pleno das capacidades intelectuais, físicas, técnico-tecnológicas e culturais do discente com vistas a sua ascensão social, quer seja na construção de sua identidade pessoal, na afirmação da autonomia, no exercício da profissão ou na busca de melhores condições de vida. Diante desses desafios da sociedade contemporânea, é preciso considerar o Ensino Médio Integrado à EPT como potencialidade nessa direção.

Considerando a realidade da maioria dos jovens brasileiros, que são vitimados pelas desigualdades sociais, levados a iniciar sua vida profissional antes dos 18 anos de idade para garantir sua sobrevivência, sendo este um fato que favorece o capital e reforça as degradações sociais, Moura, Lima Filho e Silva (2015). Esse ingresso precoce no mundo do trabalho pode cercear a continuidade dos estudos desses jovens e rebaixar os níveis de escolaridade, submetendo uma parcela considerável da população ao subemprego. Neste sentido, compreende-se que provocar o debate que impulsione o ensinar no caminho da resistência, torna-se indispensável.

É importante salientar que não podemos falar de educação sem recorrer às relações históricas de produção da vida, uma vez que estas são indissociáveis. Como apresenta a concepção marxista, de acordo com Maldaner (2016).

\footnotetext{
Neste sentido, Marx, coerente com o fundamento básico de sua concepção, toma a atividade material como a primeira e a mais fundamental instância educativa do homem. Isto porque, de sua perspectiva, é pelo trabalho que o homem aprende a dominar a natureza e essa ação do homem pressupõe o conhecimento necessário a esta tarefa. Assim, esse processo, cujo resultado é fundamentalmente educação, compreende 0 conhecimento já acumulado e disponível pela humanidade, como também a compreensão de suas debilidades e os recursos necessários para dominar sua própria natureza, adequando-as às exigências produtivas. (MALDANER, 2016, p. 12).
}

Nessa perspectiva, é indispensável considerar as relações humanas de construções sociais, culturais, econômicas e históricas, e refletir sobre as práticas interdisciplinares no ensino médio integrado à formação profissional e 
tecnológica. Para prosseguir com as considerações e reflexões propostas por este estudo, fez-se necessário a delimitação de alguns objetivos, diante da amplitude da temática abordada.

Os objetivos deste trabalho são: ( I ) examinar os aspectos sócio históricos da EPT e as políticas públicas que endossam a legislação atual, ( II ) discutir a interdisciplinaridade e suas potencialidades para a construção de um currículo mais abrangente, em termos de formação politécnica do aluno, e ( III ) analisar as orientações para o ensino interdisciplinar constantes da Base Nacional Comum Curricular-BNCC.

E com a convicção de que a educação pode contribuir com a produção do conhecimento e com uma sociedade igualitária e justa, este trabalho justifica-se pela urgência em somar vozes às lutas contra hegemônicas e a favor da formação integral. E inscreve como ação que, por meio da pesquisa educacional, visa implantar práticas educativas críticas e libertadoras. Pesquisar o currículo é o mesmo que intervir colaborativamente para a inovação do ensino e atualização dos conhecimentos necessários (SACRISTÁN, 2000), em tempos de crises e de reformas de paradigmas da sociedade brasileira.

\section{A EDUCAÇÃO PROFISSIONAL E TECNOLÓGICA: DESAFIANDO O HISTÓRICO COMO POTENCIAL PARA A FORMAÇÃO OMNILATERAL.}

A educação assim como o trabalho é parte do ser do homem e acompanha sua evolução em um movimento dialético que molda as vivências e é por elas construída, pois "Trabalho e educação são atividades especificamente humanas. Isso significa que, rigorosamente falando, apenas 0 ser humano trabalha e educa." (SAVIANI, 2007, p. 152).

Como adverte (VIEIRA; SOUZA JUNIOR, 2016, p. 153), "Não é exagerado afirmar que a educação profissional e tecnológica (EPT) acompanha o homem desde os tempos mais remotos, quando se transferiram os saberes e técnicas profissionais pela observação, pela prática e pela repetição." Ainda assim a sistematização e expansão dos conhecimentos é um fenômeno histórico advindo das necessidades sociais do desenvolvimento e meio de produção, Saviani (2007).

Nesse sentido, Saviani (2007) esclarece ainda que, o modo de produzir a vida passa ao longo da história, por mudanças que provoca a divisão social em classes, e a educação segue essa lógica. O que conduz ao dualismo estrutural, separa a formação para o trabalho intelectual, de uma outra para o trabalho manual, e resulta em desigualdades, exploração e empobrecimento da maioria da sociedade. E forma um sistema configurado entre os que controlam os meios de produção, as riquezas e o poder, sendo o outro lado dessa moeda, o povo, o proletariado, ou seja, os que vendem sua força de trabalho para sobreviver.

Os problemas e mazelas produzidos pelo capital têm provocado, ao longo da história social o inconformismo. E, ao mesmo tempo, instigado 
estudos e debates sobre a luta por um modelo alternativo de produção e organização da sociedade, o que, por sua vez, têm suscitado o entendimento da educação como um dos principais caminhos para uma outra sociedade. Decorrente disso, um olhar emerge sobre a educação como potencial transformador. O estudo de Maldaner (2016) elucida que

[...] Marx não escreveu nenhum tratado sobre a educação. As questões, relativas à educação fazem parte do contexto mais amplo de sua obra e aparecem em alguns de seus escritos, a exemplo de n'O Capital (Marx, 1996b), Manifesto do Partido Comunista (Marx; Engels, 1998) e Crítica ao Programa de Gotha (Marx, 2012). (MAIDANER, 2016, p. 15).

A respeito do exposto no excerto em tela, o estudo de Moura; Lima Filho e Silva (2015, p. 1060) trazem esclarecimentos bastante pertinentes. Embora nem Marx e nem Engels abordaram "educação, ensino ou formação profissional" especificamente, suas considerações sobre a problemática em pauta, giram em torno de reflexões que estão pulverizadas no conjunto de suas obras sobre como a população trabalhadora produz "a vida em meio às relações sociais e de produção" sob os imperativos do capitalismo. Embora a educação não foi apreendida em si mesma, na obra dos dois autores, foi mediante o entendimento da relação determinante entre educação e trabalho (sobre como se dá a produção da existência humana) que Marx e Engels puderam proceder a formulação - instrução e trabalho - que por seu turno, constituem os fundamentos das reflexões teóricas-conceituais sobre educação nos escritos marxianos e engelsianos.

O papel formativo do trabalho ajuda a compreender a importância da Educação Profissional e Tecnológica, na busca por outra conformação social, e favorece o entendimento de que a educação é um elemento de transformação das relações sociais, culturais e econômicas. E reforça a necessidade do pleno desenvolvimento das capacidades humanas, para libertar os seres da exploração e alienação impostas pelo capitalismo.

\footnotetext{
Partindo do pressuposto do trabalho como princípio educativo, a escola unitária de Gramsci procura unir formação humanista e cultura geral com educação para a vida produtiva e profissional, superando a histórica oposição entre trabalho intelectual e trabalho manual. (MALDANER, 2011, p. 61).
}

Apesar de todas as manifestações teóricas e propostas que buscam uma realidade diferente, e que alertam para a crítica condição de vida das massas no sistema capitalista, as disputas dos diferentes interesses de classes perduram, ao passo que este sistema assume novas configurações com as modernizações tecnológicas e a globalização. Mas as transformações no sistema capitalista geram contradições e permitem pressões sociais, que convertidas em políticas educacionais, abrem possibilidades para avanços na educação. Logo, esses fatos podem favorecer a construção de uma outra 
realidade socioeducacional, por meio da valorização da EPT, como potencialidade para a formação politécnica.

Posto isso, o estudo de Moura; Lima Filho e Silva $(2015,1060)$ discute que a concepção de formação omnilateral está "incorporada à tradição marxiana sob a denominação de politecnia ou educação politécnica". Sua finalidade se direciona à superação da ordem do sistema produtivo que, historicamente tem subordinado educação e trabalho a serviço da produção capitalista.

Trata-se de uma educação voltada para a emancipação da classe trabalhadora tendo como base conceitual os princípios marxianos e engelianos de omnilateralidade, politecnia, formação integral, além da concepção gramsciana de escola unitária. Suas proposições estão direcionadas à integração das dimensões da vida - trabalho, ciência, tecnologia e cultura como eixos estruturantes do processo formativo (MOURA; LIMA FILHO; SILVA; 2015; MOURA, 2016).

Esses aportes sinalizam para o entendimento de que, no campo da EPT, em se tratando da organização curricular e das práticas de ensino, a formação politécnica ou omnilateral, conforme os princípios mencionados, deve estar articulada à base dos conhecimentos das dimensões da vida concernentes às condições mentais ou intelectuais, físicas, e tecnológicas do discente.

Observa-se que a politecnia se articula à formulação de uma educação integrada, com vistas à uma formação centrada no desenvolvimento geral do profissional dotando ele não apenas com os conhecimentos necessários à performance de um ofício, mas que amplia suas chances de ascensão social "acima do nível das classes superior e média" e de "indivíduo integralmente desenvolvido" (MOURA; LIMA FILHO; SILVA; 2015; p. 1061).

Assim independentemente das divisões históricas na educação que direciona a formação profissional para uma realidade de servir ao capitalismo como instrumentalização de mão de obra, à seus moldes. A educação profissional apresenta-se como potencialidade para a preparação dos seres para a vida e para o trabalho, se romper com seu histórico, e caminhar em direção à formação humana integral. Valendo-se das contradições do sistema capitalismo e das contribuições de estudiosos que se mantém na resistência em prol de um ensino transformador e omnilateral.

\section{1. CENÁRIO SOCIOPOLÍTICO DA EDUCAÇÃO PROFISSIONAL E TECNOLÓGICA NO BRASIL}

No Brasil a educação sistematizada mantém a dualidade sendo a formação propedêutica direcionada para os dirigentes e detentores do poder, e a formação profissional assume um viés assistencialista, destinada aos desafortunados, a fim de garantir uma ocupação para os órfãos, preparando-os para o desempenho de um ofício, com objetivo de controlar a marginalização e violência, mediante a criação dos Liceus de Artes e Ofícios, como observa, Vieira; Souza Junior (2016). 
Esse movimento continua com a criação das Escolas de Aprendizes Artífices por meio do Decreto № 7.566, de 23 de setembro de 1909, sancionado pelo Presidente Nilo Peçanha, e foi um marco para o ensino técnico no Brasil, "caracterizando-se como política pública moralizadora da formação do caráter pelo trabalho", (VIEIRA; SOUZA JUNIOR, 2016, p. 156). Sofrendo posteriores alterações e expansões que acompanharam a evolução industrial do país, passa a ser prevista na Constituição de 1937, e mantém a postura assistencialista, reforçando a dualidade educacional e a diferenciação de classes sociais.

Seguindo os caminhos da evolução da organização educacional, a segunda Lei n. 9.394/96, Lei de Diretrizes e Bases da Educação Brasileira, retira o caráter assistencialista da educação profissional, e avança na proposta de uma educação integral, mas não alcança a superação do dualismo estrutural. Em um movimento de idas e vindas de instrumentos reguladores, a divisão entre ensino preparatório para vida acadêmica e para profissionalização segue ao longo de nossa história.

A exemplo, a instauração do Decreto 2.208/97, reforça a dualidade estrutural entre educação propedêutica e profissional, com esta segunda assumindo um caráter profissionalizante, com a preocupação apenas de preparar para as atividades de trabalho em níveis intermediários, sem valorizar as múltiplas capacidades dos seres. Sendo revogado posteriormente.

A gênese das controvérsias que cercam a revogação do Decreto $n$. 2.208/97 e a publicação do Decreto n. 5.154/2004 está nas lutas sociais dos anos 1980, pela redemocratização do país e particular, a mobilização do Fórum Nacional em Defesa da Escola Pública, em defesa de um sistema público e gratuito de educação, que deveria tomar forma no capítulo sobre a educação na Constituinte e em uma nova Lei de Diretrizes e Bases da Educação. (FRIGOTTO; CIAVATTA, RAMOS, 2010 p. 22).

Movimento que impulsionou algumas mudanças positivas, em vista de documentos que refletem os esforços políticos em ajustar a educação aos interesses de uma elite conservadora, que prima por implementação de políticas emergenciais para a rápida especialização de mão de obra em detrimento da formação integral, sob a camuflagem do discurso de ações em prol do desenvolvimento industrial e comercial do País.

Como consequência, o Decreto n. 5.154/2004 que permite a integração do ensino técnico de nível médio ao ensino médio, e a Lei n. 11.892/2008 que institui a Rede Federal de Educação Profissional, Científica e Tecnológica. Essa lei cria os Institutos Federais de Educação, Ciência e Tecnologia, diante de um cenário de lutas e reivindicações sociais na educação e na política, com a eleição de um "governo democrático popular", segundo (FRIGOTTO, CIAVATTA, RAMOS, 2010, p. 22).

Do exposto observa-se que, mesmo com os avanços em termos de leis, decretos e o surgimento de uma nova institucionalidade com a criação dos Institutos Federais, no contexto brasileiro, a relação educação e trabalho ainda 
permanece marcada pela oposição entre formação propedêutica e formação profissional. Estudos no campo da política educacional para EPT (MOURA, 2010; RAMOS, 2010; MOURA; LIMA FILHO; SILVA, 2015; VIEIRA; SOUZA JUNIOR, 2016; CURY; REIS; ZANARDI, 2018, entre outros) corroboram as asserções postas aqui. Encontram respaldo em estudos recentes sobre política de EPT, indicam que educação e trabalho estão marcados pela oposição entre educação propedêutica e educação profissional.

Atualmente, reformas curriculares para o ensino médio, consoante disposições da Lei 13.415/2017 e proposições da atual BNCC, intensificam essa dualidade histórica e sustentam a separação dos eixos de conhecimentos gerais daqueles para o mundo do trabalho conferindo a formação técnica 0 estatuto de itinerário formativo, mantendo esta base de saber separada da escolarização dos jovens.

Assim, contrariamente à integração do ensino médio à formação para o trabalho, o Artigo 36 da Lei 13.415/2017 a qual institui a BNCC estabelece novo conceito de "itinerário formativo" no formato de atividades e de cursos relacionados à formação técnica e profissional, mediante parcerias públicoprivadas, que podem ser aceitos pelas instituições formadoras, independente de vinculação à $B N C C$.

A BNCC tem como função orientar a organização curricular da rede nacional de educação brasileira, uma de suas principais contradições está relacionada ao seu caráter prescritivo que qualifica educação e currículo sob uma perspectiva unidirecionada, como se todos os conhecimentos pudessem ser aplicáveis a todos os discentes da educação básica.

Acerca desta assertiva, Cury, Reis e Zanardi (2018) expõem que o documento em questão

[...] serviria para superar as desigualdades evidentes em nosso sistema educacional. Ela se envolve em uma visão de escolarização que, para termos uma educação de qualidade seria necessário proporcionar conteúdos idênticos para possibilitar uma igualdade de oportunidade entre os educandos. (CURY; REIS; ZANARDI, 2018, p. $61)$.

O excerto em destaque revela que, embora a BNCC apresente propostas que visam a superação da desigualdade e da deficiência educacional brasileira, o discurso que emana do referido texto oficial sustenta uma visão classista e impositiva do conhecimento ao publica alvo, sem levar em conta sua heterogeneidade, seus anseios e limitações o que fere o direito de aprendizagem.

A obra dos autores citados trazem contribuições bastante pertinentes que elucidam o caráter regimental da BNCC, já que esta diretriz se enquadra na categoria de um projeto regimental que visa a normatização de currículos sob o modelo de competências e habilidades numa perspectiva conteudística pautada por um discurso que suaviza seu teor prescritivo em direitos de aprendizagem. 
[...] ter a BNCC como prescrição ignora o potencial curricular do cotidiano, das experiências vividas, das problematizações não respondidas, das violências sofridas, das desigualdades naturalizadas, que necessitam ser incorporadas ao conhecimento a ser escolarizado (CURY; REIS; ZANARDI, 2018, p. 103).

Em face da recente configuração política direcionada à educação e a formação técnica e profissional, torna se premente a luta pela resistência mediante o entendimento da nova realidade que se impõe sobre a organização curricular e do empreendimento de ações didático-pedagógica condizentes com os anseios e a necessidade do público alvo. Neste cenário de mudanças de paradigmas é preciso manter os debates e mobilizações frente a políticas arbitrárias de negação do caminhar rumo à formação omnilateral. Consciente da complexidade dos problemas emergentes das políticas reguladoras de nossa educação, reagir criticamente e manter o diálogo sobre currículo e práticas educacionais interdisciplinares com vistas a favorecer a formação integral são ações necessárias e urgentes para superar as contradições de reformas políticas envolvendo conhecimento, trabalho e educação.

\section{2. A INTERDISCIPLINARIDADE COMO POTENCIALIDADE NA CONSTRUÇÃO DE SABERES}

Na necessária busca por entender o que é interdisciplinaridade, e como esta pode colaborar na construção dos saberes, optamos por recorrer a conceituação deste termo conforme Ivani Fazenda (2002),

Interdisciplinaridade é uma nova atitude diante da questão do conhecimento, de abertura à compreensão de aspectos ocultos do ato de aprender e dos aparentemente expressos, colocando-os em questão. [...] A interdisciplinaridade pauta-se numa ação em movimento. Pode-se perceber esse movimento em sua natureza ambígua, tendo como pressuposto a metamorfose, a incerteza. (FAZENDA, 2002, p. 11, 12)

E diante da complexidade de pensar ações voltadas para uma educação seguindo os preceitos dos autores que fundamentam esse estudo, buscando contribuir com uma formação omnilateral, valorizando 0 desenvolvimento das múltiplas capacidades dos educandos. A interdisciplinaridade na concepção de Fazenda, (2002) é um direcionamento para uma movimentação ampla e crítica da forma de educar e na construção dos saberes.

Nesta perspectiva, os educadores precisam repensar suas atuações e desprender esforços para novas maneiras de educar, observando a relações entre as diversas áreas do conhecimento, buscando um trabalho conjunto 
para proporcionar um processo de ensino compatível com a realidade de inter-relação dos saberes.

Assim é urgente ter atenção para como são conduzidas questões como a interdisciplinaridade visto que,

\begin{abstract}
Normalmente, professores e educadores em geral expressam sua compreensão a partir de uma leitura imediata e linear do próprio termo interdisciplinaridade, reduzindo-o a uma prática de "cruzamento" de disciplinas, ou melhor, de partes dos conteúdos disciplinares, que eventualmente ofereçam pontos de contato nas atividades letivas. (CASCINO, 2004, p. 69).
\end{abstract}

Por isso é preciso um olhar entendendo-a como ação formativa para além das relações entre as disciplinas, como um movimento em função do integrar os diversos conhecimentos científicos em prol da construção de novas práticas, valorizando as relações produzidas no processo ensinoaprendizagem, (FAZENDA, 2002).

Nessa perspectiva, mudanças na forma de entender e trabalhar essa questão torna-se necessária e também um desafio, diante da premissa que a interdisciplinaridade é muito mais que apenas trabalhar um mesmo temachave em dado período por disciplinas que tenham afinidade. A conceituação explicitada de interdisciplinaridade conduz a observação de que existe uma relação intrínseca entre as áreas de conhecimentos e os saberes, instigandonos questionar o que está expresso nos documentos norteadores da educação brasileira.

A necessidade está na relevância dessas questões diante do pensar currículos para uma educação integral e integradora pois, "o processo interdisciplinar desempenha um papel decisivo no sentido de dar corpo ao sonho de fundar uma obra de educação à luz da sabedoria, da coragem e da humanidade", (FAZENDA, 1998, p. 8).

E desafiador por não se tratar de um processo simples e rápido, mas sim de construções que merecem estudos e debates envolvendo diversos profissionais de diferentes etapas da educação. Pois trabalhar de maneira conjunta com profissionais com distintas interpretações sobre o que é, e como deve ser tratada a interdisciplinaridade, observando as normas vigentes onde,

BNCC e currículos têm papéis complementares para assegurar as aprendizagens essenciais definidas para cada etapa da Educação Básica, uma vez que tais aprendizagens só se materializam mediante o conjunto de decisões que caracterizam o currículo em ação (BRASIL, 2018, p. 18).

Colocando sobre educadores e dirigentes das instituições de ensino a responsabilidade por decisões de como proceder e que ações implementar, desafiando-os para 0 desenvolvimento de práticas educativas mais 
abrangentes. Assim os indicativos da BNCC sobre a interdisciplinaridade proporciona uma abertura que pode ser aproveitada para a construção de um currículo interdisciplinar. Mas é preciso ressaltar que essa questão é tratada de uma maneira suavizada aumentando as tensões neste território diante das seguintes orientações,

decidir sobre formas de organização interdisciplinar dos componentes curriculares e fortalecer a competência pedagógica das equipes escolares para adotar estratégias mais dinâmicas, interativas e colaborativas em relação à gestão do ensino e da aprendizagem; (BRASIL, 2018, p. 18)

Sendo possível observar em algumas partes da BNCC as indicações para a interdisciplinaridade, ainda assim, pode-se dizer que essas são vagas em relação ao como fazer, e também contraditórias por priorizar algumas áreas do conhecimento. Apresentando um texto confuso sobre os reais direcionamentos para a educação, em especial para o Ensino Médio. Onde ao mesmo tempo que expõe um discurso de formação ampla em decorrência de uma estrutura flexível do currículo, na realidade diminui a carga horária e deixa de privilegiar áreas de relevância para a formação crítica dos sujeitos.

\begin{abstract}
As aprendizagens essenciais definidas na BNCC do Ensino Médio estão organizadas por áreas do conhecimento (Linguagens e suas Tecnologias, Matemática e suas Tecnologias, Ciências da Natureza e suas Tecnologias, Ciências Humanas e Sociais Aplicadas), conforme estabelecido no artigo 35-A da LDB. Desde que foram introduzidas nas DCNEM/1998 (Parecer CNE/CEB no 15/199856), as áreas do conhecimento têm por finalidade integrar dois ou mais componentes do currículo, para melhor compreender a complexa realidade e atuar nela. [...] As competências e habilidades da BNCC constituem a formação geral básica. Os currículos do Ensino Médio são compostos pela formação geral básica, articulada aos itinerários formativos como um todo indissociável. (BRASIL, 2018, p. 469-470).
\end{abstract}

Assim, diante das imprecisões dos documentos norteadores para educação, os diálogos em relação à relevância do currículo escolar precisa ser constantemente ampliados e enriquecidos, para que esses possam de fato cooperar com as práticas interdisciplinares. Acerca dessa assertiva, Sancristán (2013) considera que este tem se configurado como componente organizacional para a escolarização e instrumento regulador para os conteúdos e ações a serem desenvolvidos nos ambientes escolares, e alerta ainda para que,

O pensamento sobre o currículo tem de desvelar sua natureza reguladora, os códigos por meio dos quais ele é feito, que mecanismos utiliza, como é realizada essa natureza e que consequências podem advir de seu funcionamento. [...] Também é preciso explicitar, explicar e justificar as opções que são tomadas e 
o que nos é imposto; ou seja, devemos avaliar o sentido do que se faz e para o que o fazemos. (SANCRISTÁN, 2013, p. 23).

Nessa perspectiva, vale observar que as políticas públicas educacionais reguladoras expressas em forma de Leis e documentos como a BNCC, são elaboradas por governantes e representantes de várias instâncias do serviço público que são por vezes definidos por indicações políticas. Assim sendo, há que se ter atenção para as intenções intrínsecas nos documentos e indicativos para educação.

E diante dessas problemáticas, as construções curriculares precisam ser constantemente debatidas e aprimoradas, ajustando os passos de forma responsável e comprometida por diversos profissionais da educação, considerando os agentes sociais, sem abrir mão das disputas políticas, Saviani (2003). Para que não passem despercebidos os mecanismos ou a falta desses, para uma efetiva construção interdisciplinar e omnilateral da educação.

Percebendo que o currículo é também território de oportunidade de ações de valorização das multiculturalidades, especificidades regionais e locais, e entendendo que "a escola é disputada na correlação de forças sociais, políticas e culturais", e por isso cercado de regulações, normas e controles, (ARROYO, 2013, p. 13).

Ciavatta (2005), reafirma a importância da construção dos currículos como produtores de saberes e de cultura, devendo considerar a realidade e as memórias produzidas nos ambientes escolares. E em relação ao ensino médio integrado à educação profissional, Ramos (2010) adverte que a integração precisa ser além de somar os currículos, adotando "processos de ensino-aprendizagem, conhecimentos gerais e específicos; cultura e trabalho; humanismo e tecnologia" (RAMOS, 2010, p. 52).

Explicitando assim a relevância e a potencialidade da interdisciplinaridade, para uma educação que una os conhecimentos em prol de uma formação ampla e omnilateral, consoante com os apontamentos de Fazenda (2008). Preparando os educandos não apenas para o mundo do trabalho, mas para a vida, desenvolvendo suas múltiplas capacidades, viabilizando a apropriação dos conhecimentos científicos, práticos e culturais, e o desenvolvimento da criticidade necessária para o movimentar-se por uma sociedade mais justa e igual.

\section{METODOLOGIA}

Este é um estudo bibliográfico e documental, considerando que a "pesquisa é $\mathrm{O}$ ato pelo qual procuramos obter conhecimento sobre alguma coisa" (GATTI, 2010, p. 9), a busca por conhecimentos específicos sobre o tema levou ao referencial e a observação de documentos relevantes para a demarcação de critérios norteadores desta pesquisa. 
Nesse percurso de propor considerações sobre a interdisciplinaridade e sua relevância para a educação Profissional e Tecnológica no Nível Médio, este trabalho recorre à fontes bibliográficas teóricas sobre a relação existente entre trabalho e educação, dualismo sócio educacional e as disputas e possibilidades para a construção de um currículo integrado.

Considerando uma formação do discente para a vida e para o trabalho, os diálogos estão embasados nas contribuições de estudiosos filiados à corrente teórico-epistemológica marxista, a saber (ARROYO, 2013; CIAVATTA, 2005; MALDANER, 2016; MOURA; LIMA; SILVA, 2015; RAMOS, 2010; SAVIANI, 2007; VIEIRA; SOUZA JUNIOR, 2016), contribuintes para pesquisas no terreno educação. Com proposições para o desenvolvimento de currículos que integrem conteúdos politécnicos, observando também as questões sobre, sem deixar de fora a memória, a cultura e a história das políticas públicas da EPT.

A escolha pelo caráter bibliográfico desta pesquisa encontra reforço nas palavras de Gil (2008),

A principal vantagem da pesquisa bibliográfica reside no fato de permitir ao investigador a cobertura de uma gama de fenômenos muito mais ampla do que aquela que poderia pesquisar diretamente. Esta vantagem se torna particularmente importante quando 0 problema de pesquisa requer dados muito dispersos pelo espaço. [...] A pesquisa bibliográfica também é indispensável nos estudos históricos (GIL, 2008, p. 69).

Para alcançar os objetivos propostos por este trabalho a observação dos instrumentos legais que direcionam a educação no Brasil também foi fundamental. Analisando os caminhos que a Educação Profissional e Tecnológica deve assumir e os elementos a considerar na sua composição curricular. A pesquisa documental, percorre caminhos semelhantes e em alguns casos até complementares aos da bibliográfica, como elucida GIL, (2008),

\footnotetext{
diferença entre ambas está na natureza das fontes. Enquanto a pesquisa bibliográfica se utiliza fundamentalmente das contribuições dos diversos autores sobre determinado assunto, a pesquisa documental vale-se de materiais que não receberam ainda um tratamento analítico, ou que ainda podem ser reelaborados de acordo com os objetivos da pesquisa. (GIL, 2008, p. 69).
}

Tendo em vista o momento de tensões decorrentes das ações e propostas do atual governo para a educação, manter os diálogos sobre as práticas e ações interdisciplinares que podem favorecer os currículos em prol de uma formação para a vida e não apenas para atender demandas do mercado de trabalho, é caminhar em direção à resistência, é movimentar-se 
por uma formação humana integral e para a superação da atual estrutura social.

\section{CONSIDERAÇÕES FINAIS}

A educação tem um forte vínculo com o trabalho e com a forma como a sociedade se constitui. Ciente de que colocar em evidência a potencialidade transformadora da Educação Profissional e Tecnológica, pode representar para os que se beneficiam com o sistema capitalista algo ameaçador, pois esse movimento pode contribuir na luta por mudanças substanciais nas configurações sociais, por meio da união do trabalho à educação e a superação da dicotomia educacional.

Considerando que proporcionar uma formação ampla e integral aos filhos dos trabalhadores pode ocasionar uma transformação social e cultural, capaz de progredir na direção da superação da sociedade de classes, diminuindo as desigualdades sociais por meio da preparação desses sujeitos para a vida laboral e para a continuidade de estudos e aperfeiçoamentos.

Nesse sentido, Ramos (2010) admite que o ensino médio integrado nos moldes que se expressa hoje pode ser o melhor caminho para a politecnia, indicando a responsabilidade dos que buscam contribuir com a educação, em permanecer na luta e nas ações de construção da politecnia. Destacando a possibilidade de uma nova forma de educar, mesmo em momentos adversos, que torne os seres ainda mais humanos e livres.

Assim, alternativas como as práticas interdisciplinares no ensino médio integrado à formação profissional e tecnológica que viabilizem a união dos conhecimentos, contribuindo com a formação omnilateral como força potencial de valorização dos sujeitos, pode despertar os educandos para uma postura crítica reflexiva. E favorecer a compreensão da aplicabilidade real dos conhecimentos científicos, sob a lógica de que na prática para atuar nas mais diversas profissões em tempos de globalização, faz-se necessário o domínio de saberes diversos.

Para além da atuação profissional, esses saberes diversos podem e devem alcançar os acontecimentos sociais, políticos e culturais e a participação nos processos que exigem uma visão integradora de muitas variantes. Possibilitando aos jovens o desenvolvimentos de suas múltiplas capacidades rompendo com a instrumentalização nos moldes do sistema capitalista, preparando os sujeitos para o trabalho e para vida.

Nessa perspectiva, as considerações deste trabalho aponta ao entendimento da relevância da interdisciplinaridade como possibilidade de integração de saberes de várias áreas do conhecimento em prol de uma formação ampla e crítica dos educando. Mas consciente de que estas práticas ainda são um desafio para educadores e agentes reguladores, sendo que as questões em torno da interdisciplinaridade no ensino médio integrado evidenciam a necessidade de instigar o debate e estudos que busquem seu fomento, diante da forma superficial que está disposta nos atuais documentos 
norteadores da educação.

Concluindo assim, que é preciso continuar buscando o desenvolvimento e o aprimoramento de práticas que contribuem para a educação, fortalecendo os movimentos de resistência à atual forma de produção, oportunizando aos jovens uma educação de nível médio que os subsidiem em suas pretensões futuras, sejam essas de iniciar na vida laboral ou de continuar sua formação em nível acadêmico.

\section{REFERÊNCIAS}

ARROYO, Miguel. Currículo, território em disputa. 5.ed. Petrópolis, RJ: Vozes, 2013.

BRASIL. Constituição dos Estados Unidos do Brasil de 10 de nov. 1937. Diário Oficial da União, Brasília, DF, 10 nov. 1937. Disponível em: http://www.planalto.gov.br/ccivil_03/constituicao/constituicao37.htm. Acesso em: 28 fev. 2020.

BRASIL. Decreto n. 7.566 de 23 de setembro de 1909. Cria nas Capitais dos Estados da República Escolas de Aprendizes Artífices, para o Ensino Profissional Primário e Gratuito. Publicação Original [Coleção de Leis do Brasil de 31/12/1909 - vol. 002] (p. 445, col. 1). Disponível em: http://legis.senado.leg.br/norma/589450. Acesso em: 28 de fev. 2020.

BRASIL. Lei n. 11.892, de 29 de dezembro de 2008. Institui a Rede Federal de Educação Profissional, Científica e Tecnológica, cria os Institutos Federais de Educação, Ciência e Tecnologia. Brasília, DF, 29 dez. 2008. Disponível em: http://www.planalto.gov.br/ccivil_03/_Ato2007-2010/2008/Lei/L11892.htm. Acesso em: 20 dez. 2019.

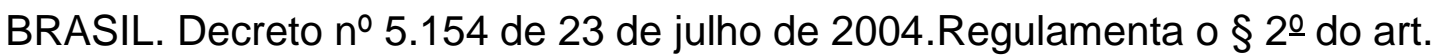
36 e os arts. 39 a 41 da Lei ㄲo 9.394, de 20 de dezembro de 1996, que estabelece as diretrizes e bases da educação nacional, e dá outras providências. Diário Oficial da União, Brasília, DF, 26 jul. 2004. Disponível em: http://www.planalto.gov.br/ccivil_03/_ato2004-2006/2004/decreto/d5154.htm. Acessado em 26 fev. 2020.

BRASIL. Lei no 13.415 de 16 de fevereiro de 2017. Institui a Política de Fomento à Implementação de Escolas de Ensino Médio em Tempo Integral. Diário Oficial da União, Brasília, DF, 17 fev..2017. Disponível em: http://www.planalto.gov.br/ccivil_03/_Ato2015-2018/2017/Lei/L13415.htm. Acesso em: 27 de fev. 2020.

Ministério da Educação. Base Nacional Comum Curricular (BNCC). Brasília, DF, 2018. Disponível em:

http://basenacionalcomum.mec.gov.br/images/BNCC_EI_EF_110518_versaofin al_site.pdf. Acesso em: 28 de fevereiro de 2020.

CASCINO, Fabio. Educação Ambiental: princípios, história, formação de professores. 4 ed. São Paulo: Editora Senac São Paulo, 2004. 
CIAVATTA, Maria. A formação integrada a escola e o trabalho como lugares de memória e de identidade. Trabalho necessário. vol. 3, n. 3, 2005. DOI: https://doi.org/10.22409/tn.3i3.p6122. Acesso em: 20 de fevereiro de 2020.

CURY, Carlos Roberto Jamil; REIS, Magali; ZANARDI, Teodoro Adriano Costa. Base Nacional Comum Curricular: dilemas e perspectivas. São Paulo: Cortez, 2018.

FAZENDA, Ivani C. (org.). Dicionário em construção: interdisciplinaridade. 2. ed. São Paulo: Cortez, 2002.

FAZENDA, Ivani C. (org.). O que é interdisciplinaridade?. São Paulo: Cortez, 2008.

FAZENDA, Ivani C. A. (org.). Didática e interdisciplinaridade. Campinas, SP: Papirus, 1998.

FRIGOTTO, Gaudêncio; CIAVATTA, Maria; RAMOS, Marise (Org.). Ensino médio integrado: concepções e contradições. 2. ed. São Paulo: Cortez, 2010.

GATTI, Bernadete Angelina. A construção da pesquisa em educação no Brasil. 3 ed. Brasília: Liber Livro Editora, 2010.

GIL, Antonio Carlos. Métodos e técnicas de pesquisa social. 6. ed. São Paulo: Atlas, 2008.

MALDANER, Jair José. Considerações sobre trabalho e educação em Marx. Revista Filosofazer, Passo Fundo, v. 49, n. 27, p. 9-20, jul./dez. 2016. ISSN 2526-5709. Disponível em:

http://filosofazer.ifibe.edu.br/index.php/filosofazer/article/view/212. Acesso em: 01 nov. 2019.

MALDANER, Jair José. Considerações sobre a educação em Gramsci. Revista Filosofazer, Passo Fundo, v. 38, p. 61-69, jan./jun. 2011. ISSN 2526-5709.

MANACORDA, Mario Anghiero. O Princípio educativo em Gramsci. Porto Alegre: Artmed, 1990. p.201 a 207.

MOURA, Dante Henrique. Ensino Médio e educação profissional: dualidade histórica e possibilidade de integração. In: MOLL, Jaqueline (Org.). Educação Profissional e Tecnológica no Brasil Contemporâneo: desafios, tensões e possibilidades. Porto Alegre: Artmed. 2010.

MOURA, DANTE HENRIQUE; LIMA FILHO, DOMINGOS LEITE; SILVA, MÔNICA RIBEIRO. Politecnia e formação integrada: confrontos conceituais, projetos políticos e contradições históricas da educação brasileira. Rev.

Bras. Educ., Rio de Janeiro, v. 20, n. 63, p. 1057-1080, dez. 2015. Disponíel em: http://dx.doi.org/10.1590/S1413-24782015206313. Acesso em: $10 / 01 / 2020$

MOURA, D. H. Entrevista. RECEI Revista Ensino Interdisciplinar, v. 2, no․ 05, Julho/2016, UERN, Mossoró, RN. Disponivel em:

http://docplayer.com.br/113680725-Recei-revista-ensino-interdisciplinar-v-2-no05-julho-2016-uern-mossoro-rn.html. Acesso em: 28/02/2020.

RAMOS, Marise. Ensino médio integrado: ciência, trabalho e cultura na relação 
entre educação profissional e educação básica. In: MOLL, Jaqueline (Org.) e (colaboradores). Educação profissional e tecnológica no Brasil contemporâneo: desafios, tensões e possibilidades. Porto Alegre: Artmed. 2010.

SACRISTÁN, José Gimeno. O currículo: uma reflexão sobre a prática. 3 ed. Porto Alegre: ArtMed, 2000.

SACRISTÁN, José Gimeno.(org.). Saberes e incertezas sobre o currículo. São Paulo: Penso, 2013.

SAVIANI, Dermeval. Trabalho e educação: fundamentos ontológicos e históricos. Revista Brasileira de Educação. Rio de Janeiro, v. 12, n. 34, p.152-165, jan./abr. 2007. Disponível em: http://www.scielo.br/pdf/rbedu/v12n34/a12v1234.pdf. Acesso em: 28/02/2020. SAVIANI, Dermeval. O choque teórico da Politecnia. Trab. educ. saúde, Rio de Janeiro, v. 1, n. 1, p. 131-152, Mar. 2003. Disponivel em: http://dx.doi.org/10.1590/S1981-77462003000100010. Acesso em: 18/02/2020. VIEIRA, Alboni Marisa Dudeque Pianovski; SOUZA JUNIOR, Antonio de. A educação profissional no Brasil. Rev. Interacções, Santarém - Portugal, vol. 12 n. $.40,2016$, p. 152-169, 17 de janeiro de 2017. Disponível em: DOI: https://doi.org/10.25755/int.10691. Acesso em: 31 out. 2019. 